Document downloaded from:

http://hdl.handle.net/10251/58330

This paper must be cited as:

Patiño Quinchía, JE.; Juan Carlos Duque; Pardo Pascual, JE.; Ruiz Fernández, LÀ. (2014). Using remote sensing to assess the relationship between crime and the urban layout. Applied Geography. 55:48-60. doi:10.1016/j.apgeog.2014.08.016.

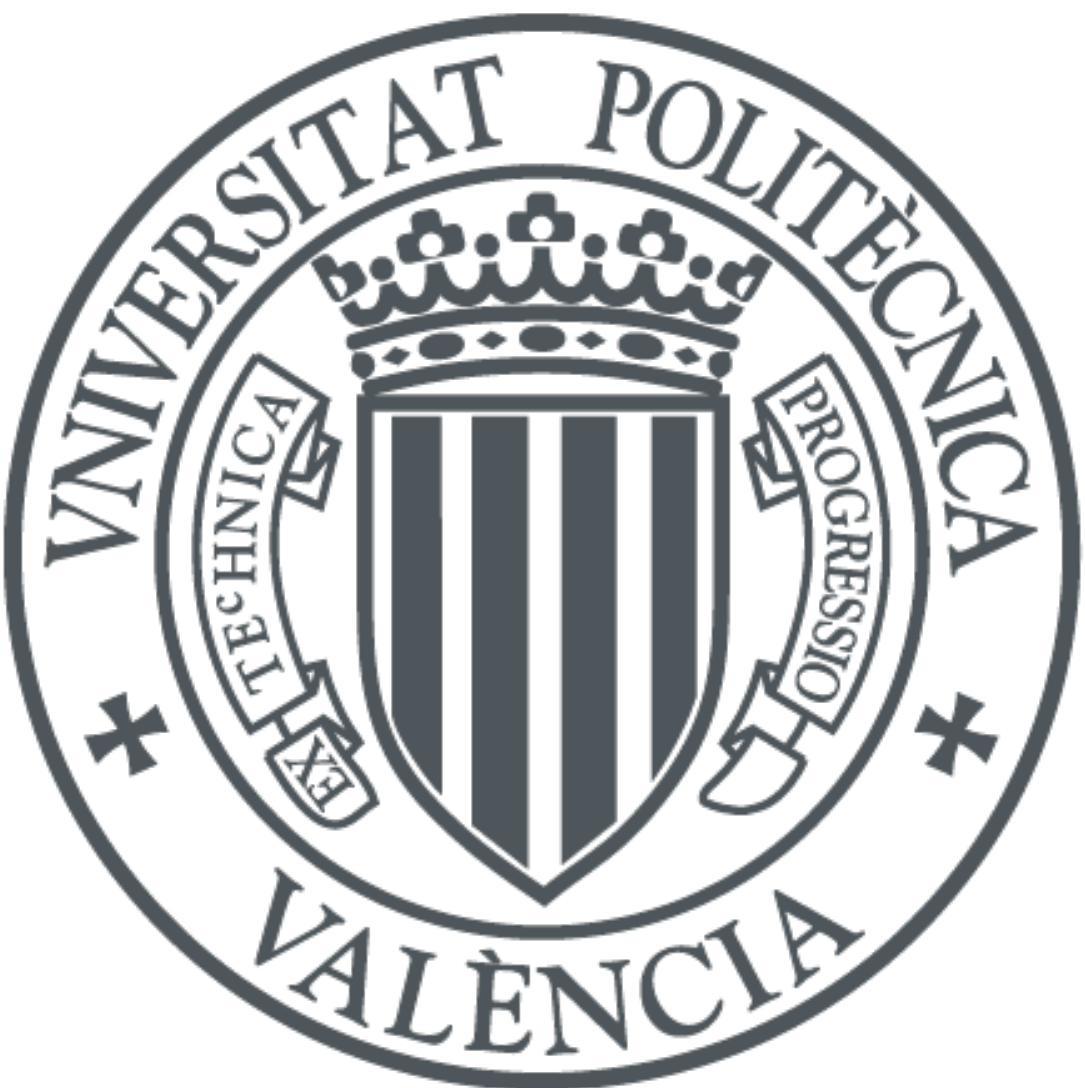

The final publication is available at

http://dx.doi.org/10.1016/j.apgeog.2014.08.016

Copyright Elsevier

Additional Information 


\title{
Using remote sensing to assess the relationship between crime and the urban layout
}

\author{
Jorge E. Patino \\ Juan C. Duque \\ Josep E. Pardo-Pascual \\ Luis A. Ruiz
}

2014

\author{
Jorge E. Patino (corresponding author) \\ Research in Spatial Economics (RiSE group), Department of Economics, EAFIT University, \\ Carrera 497 Sur - 50, Medellin, Colombia \\ e-mail: jpatinoq@eafit.edu.co \\ Juan C. Duque \\ Research in Spatial Economics (RiSE group), Department of Economics, EAFIT University \\ Carrera 497 Sur - 50, Medellin, Colombia \\ e-mail: jduquec1@eafit.edu.co \\ Josep E. Pardo-Pascual \\ Geo-Environmental Cartography and Remote Sensing Group, Universitat Politècnica de València, \\ Camino de Vera, s/n, 46022, Valencia, Spain \\ e-mail: jepardo@cgf.upv.es \\ Luis A. Ruiz \\ Geo-Environmental Cartography and Remote Sensing Group, Universitat Politècnica de València, \\ Camino de Vera, s/n, 46022, Valencia, Spain \\ e-mail: laruiz@cgf.upv.es
}




\title{
Using remote sensing to assess the relationship between crime and the urban layout
}

\begin{abstract}
The link between place and crime is at the base of social ecology theories of crime that focus in the relationship of the characteristics of geographical areas and crime rates. The broken windows theory states that visible cues of physical and social disorder in a neighborhood can lead to an increase in more serious crime. The crime prevention through environmental design (CPTED) planning approach seeks to deter criminal behavior by creating defensible spaces. Based on the premise that a settlement's appearance is a reflection of the society, we ask whether a neighborhood's design has a quantifiable imprint when seen from space using urban fabric descriptors computed from very high spatial-resolution imagery. We tested which land cover, structure and texture descriptors were significantly related to intra-urban homicide rates in Medellin, Colombia, while controlling for socioeconomic confounders. The percentage of impervious surfaces other than clay roofs, the fraction of clay roofs to impervious surfaces, two structure descriptors related to the homogeneity of the urban layout, and the uniformity texture descriptor were all statistically significant. Areas with higher homicide rates tended to have higher local variation and less general homogeneity; that is, the urban layouts were more crowded and cluttered, with small dwellings with different roofing materials located in close proximity to one another, and these regions often lacked other homogeneous surfaces such as open green spaces, wide roads, or large facilities. These results seem to be in agreement with the broken windows theory and CPTED in the sense that more heterogeneous and disordered urban layouts are associated with higher homicide rates.
\end{abstract}

\section{Keywords:}

Remote sensing, urban layout characterization, Broken windows, CPTED, homicide, VHR imagery

\section{Introduction}

Macro-level or social ecology theories of crime are focused in how the characteristics of geographical areas influence crime rates, i.e., how crime rates vary by ecological units rather than how the characteristics of individuals relate to their involvement in criminal behavior (Cullen \& Agnew, 2011). Since the 19th-century, early French social ecologists Guerry and Quetelet were interested in explaining differences in community crime levels in terms of the varying social conditions of the resident population (Anselin, Cohen, Cook, Gorr, \& Tita, 2000). Social disorganization theorists linked high crime rates to neighborhood characteristics such as low income, high unemployment, ethnic heterogeneity, and residential mobility, and the impact these characteristics have on the community ability to exert social control for the prevention of crime (Shaw \& McKay, 1942). The link between place and crime is also central to the perspective of Routine Activities theory, which states that criminal acts require convergence in space and time of a motivated offender, a suitable target, and the absence of capable guardians against crime, and relates crime patterns to the everyday patterns of social interaction (Cohen \& Felson, 1979). 
Urban neighborhoods differ by the types of households they contain and by the types of physical environments they provide (Roncek, 1981), and these physical environments can influence the likelihood of crime occurrence (Taylor \& Harrell, 1996). Environmental criminology studies that have addressed the spatial distribution of crime demonstrate that certain land uses, i.e., the concentration of commercial and residential areas, are associated with crime hot spots (Anselin et al., 2000). Land use, sociodemographics, open spaces, and residential density affect the types and intensity of crimes (Salleh, Mansor, Yusoff, \& Nasir, 2012). The broken windows theory states that visible cues of physical and social disorder in a neighborhood can lead to an increase in crime (Wilson \& Kelling, 1982). Physical disorder refers to the presence of abandoned and deteriorated houses and vehicles, graffiti-painted walls and litter, and this phenomenon is also related to social disorder and the occurrence of minor offenses within a neighborhood. Similar ideas support planning approaches that seek to deter criminal behavior by designing ordered, highly visible and easily defensible urban spaces, such as crime prevention through environmental design (CPTED), and New Urbanism (Cozens, 2008). DeFrances \& Titus (1993) found that whether a burglary was completed or aborted was associated with neighborhood disorganization and home occupancy, and Keizer, Lindenberg, \& Steg (2008) tested the broken windows theory in six field experiments and reported that when people observe that others have violated certain social norms or legitimate rules, they are more likely to violate other norms and rules, causing disorder to spread and escalate.

Previous research addressed the relationships between crime in urban settings and physical and environmental variables such as altitude and slope (Breetzke, 2012), temperature and weather conditions (Anderson \& Anderson, 1984; Butke \& Sheridan, 2010; Carlsmith \& Anderson, 1979; Cohn \& Rotton, 2000; DeFronzo, 1984; Field, 1992; Salleh et al., 2012; Sorg \& Taylor, 2011), vegetation (Donovan \& Prestemon, 2012; Kuo \& Sullivan, 2001; Troy, Grove, \& O’Neil-Dunne, 2012; Wolfe \& Mennis, 2012), land use (Kurtz, Koons, \& Taylor, 1998; Wilcox, Quisenberry, Cabrera, \& Jones, 2004), nighttime lighting (Weeks, 2003), and the spatial pattern of the built environment (Browning et al., 2010; Foster, GilesCorti, \& Knuiman, 2010; Shu \& Huang, 2003; Taylor \& Harrell, 1996). Cerdá et al. (2012) found reduced violence outcomes in some neighborhoods of Medellin, Colombia, that were the focus of an urban development plan that included a transportation system and public space improvements such as additional lighting, new pedestrian bridges and street paths, a library park, and buildings for schools and recreational centers. Vegetation measures and land use diversity indices in those works were derived from remote sensing imagery, and the spatial pattern descriptors were computed from expensive and time-consuming field surveys and appraisals.

Spatial effects affect crime as a phenomenon -spatial dependence and spatial heterogeneity- and these effects should be considered when investigating the relationships between crime and place (Anselin et al., 2000; Anselin, 1988). However, few studies have considered spatial effects in the literature on crime and the physical features of urban places. Another undertaken issue is the potential effects of selecting improper spatial units of analysis, such as spurious autocorrelation (Anselin, 1988) and the "ecological fallacy" (Openshaw, 1984; Robinson, 1950). Based on the hypothesis that the surface appearance of a settlement is the result of the human population's social and cultural behavior and interactions with the environment, and that people living in urban areas with similar physical housing conditions have similar social and demographic characteristics (Jain, 2008; Taubenböck et al., 2009), we use remote sensing data to investigate the relationship 
between homicide and the urban environment while controlling for potential socioeconomic confounders in Medellin, Colombia. This city is well suited for such a study because it is affected by high crime rates and because of the high variability in the urbanism and socioeconomic conditions of its neighborhoods; these factors make Medellin a useful laboratory for studying urban issues from the spatial analysis perspective.

The remainder of this paper is organized as follows. Section 2 presents the study site, the socioeconomic and remote sensing data, and the spatial unit of analysis. Section 3 describes a classic econometric model of homicide rates for Medellin and the results from including remote sensing data in that classical model. Section 4 presents a discussion of the results, and conclusions are presented in section 5.

\section{Study site and data}

\subsection{Medellin}

Medellin is the second largest city in Colombia and has a population of 2.4 million (DANE, 2012), with $93.4 \%$ of its population considering themselves white descendants (which includes mixed Spanish and indigenous Amerindian descent); another 6.5\% claim African descent, and $0.1 \%$ claim to be indigenous Amerindian (DANE, 2010). This city extends over a narrow valley crossed by Medellin River from South to North, with the most western and eastern neighborhoods of the city built over slopes steeper than $20 \%$. Medellin is a useful location for conducting intra-urban variability studies because it has experienced high population growth rates since the 1950 s owing to a combination of factors such as industrial development, which offered job opportunities, and then the political violence and the drug war in the rural areas of the country, which forced many farmers and peasants to move from rural areas to the city. Initially the city grew over the alluvial plain of the river, but in the last decades it spread towards the western and eastern slopes of the valley in an unplanned way. The rapid and unplanned urban growth exceeded the capacity of the local authorities to deliver affordable housing, public services and infrastructure in some parts of the city and resulted in the current high degree of spatial heterogeneity in both the socioeconomic and physical characteristics of its neighborhoods (Juan C. Duque, Royuela, \& Noreña, 2013): the more affluent neighborhoods are located in the West and the South parts of the city, while the less affluent are in the North and towards the urban-rural fringe in the steepest slopes of the valley in the East and West.

During the last two decades, Colombia has sustained a reputation as one of the most violent countries in the world, and Medellin is considered to be its most violent city (Giraldo Ramírez, 2010). The average annual homicide rate in the country between 1998 and 2003 was 60 homicides per 100,000 inhabitants, whereas in Medellin, the rate reached 156; from 2004 to 2009, the rates decreased to 37 for Colombia and 50 for Medellin (SISC, 2010). Homicide rates in Medellin in the late 1980s correlate with the rise in narco-violence and the strategy of guerrillas and paramilitary groups of bringing the conflict to the cities, whereas the decreasing trends have their starting points in the peace agreements with guerrillas in 1990, the end of the Medellin drug cartel and the death of Pablo Escobar in December 1993, the joint Orion operation between the police and the army to retake control over the most western part of the city in 2002, and the demobilization of paramilitary groups in December 2003 (Giraldo Ramírez, 2010). Statistics for Medellin in recent years show a decreasing trend, from 380 homicides per 100,000 inhabitants in the 
early 1990s (Gaviria, 2000) to 34 in 2007, and this number peaked again at 94 in 2009 (Giraldo Ramírez, 2010) (Figure 1).

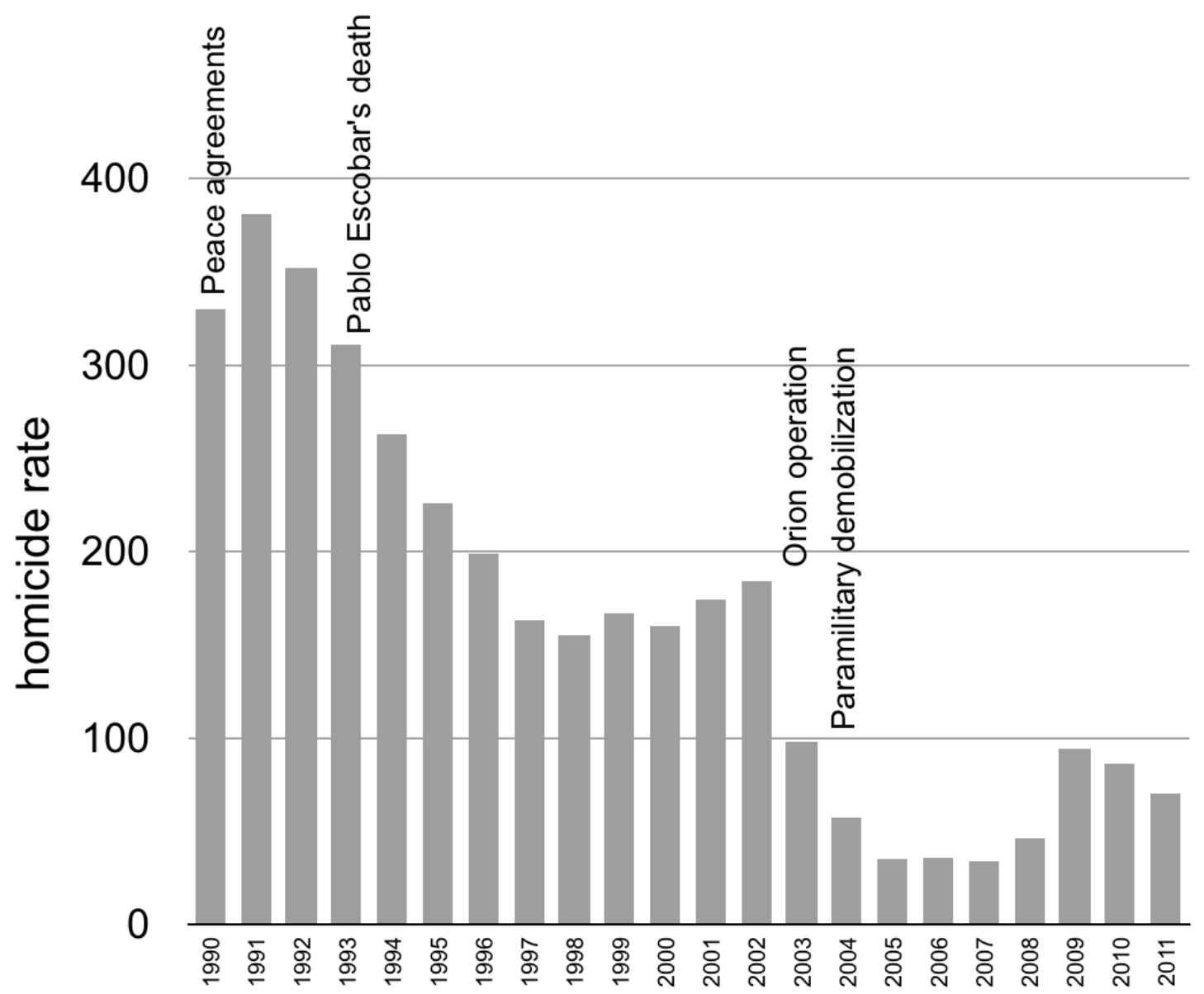

Figure 1. Medellin's annual homicide rates per 100,000 people from 1990 to 2011. Data source: Giraldo Ramírez (2010) and Medellín Cómo Vamos (2012).

\subsection{Socieconomic data and homicide counts}

Socioeconomic variables were computed from the 2005 National Census and the 2009 Quality of Life Survey of Medellin. This survey is developed annually since 2004 by the municipality of Medellin to measure standards of living throughout the city, and to have updated information at inter-census dates to inform policy making. The 2009 Quality of Life survey comprises 237 questions on 11 dimensions: housing, households, demographics, gender and family violence, education, social security, social participation, mobility, security and crime victimization, income and employment, and nutrition. The sample contains 20,782 households that represent 84,474 persons.

Homicide counts by administrative neighborhood for Medellin for the years 2010 and 2011 were provided by the Sistema de Información de Seguridad y Convivencia, SISC (Security and Conviviality Information System) of Medellin City Hall. Figure 2 shows the intra-urban variations in average homicide counts for the years 2010 and 2011 at the administrative neighborhood level in Medellin. The highest homicide counts are found in the downtown, as 
well as in some neighborhoods located in the North of the city and near the urban-rural fringe in the East, West, and Southwest. Blank areas in the map are institutional areas such as the local airport, public parks, and City Hall facilities.

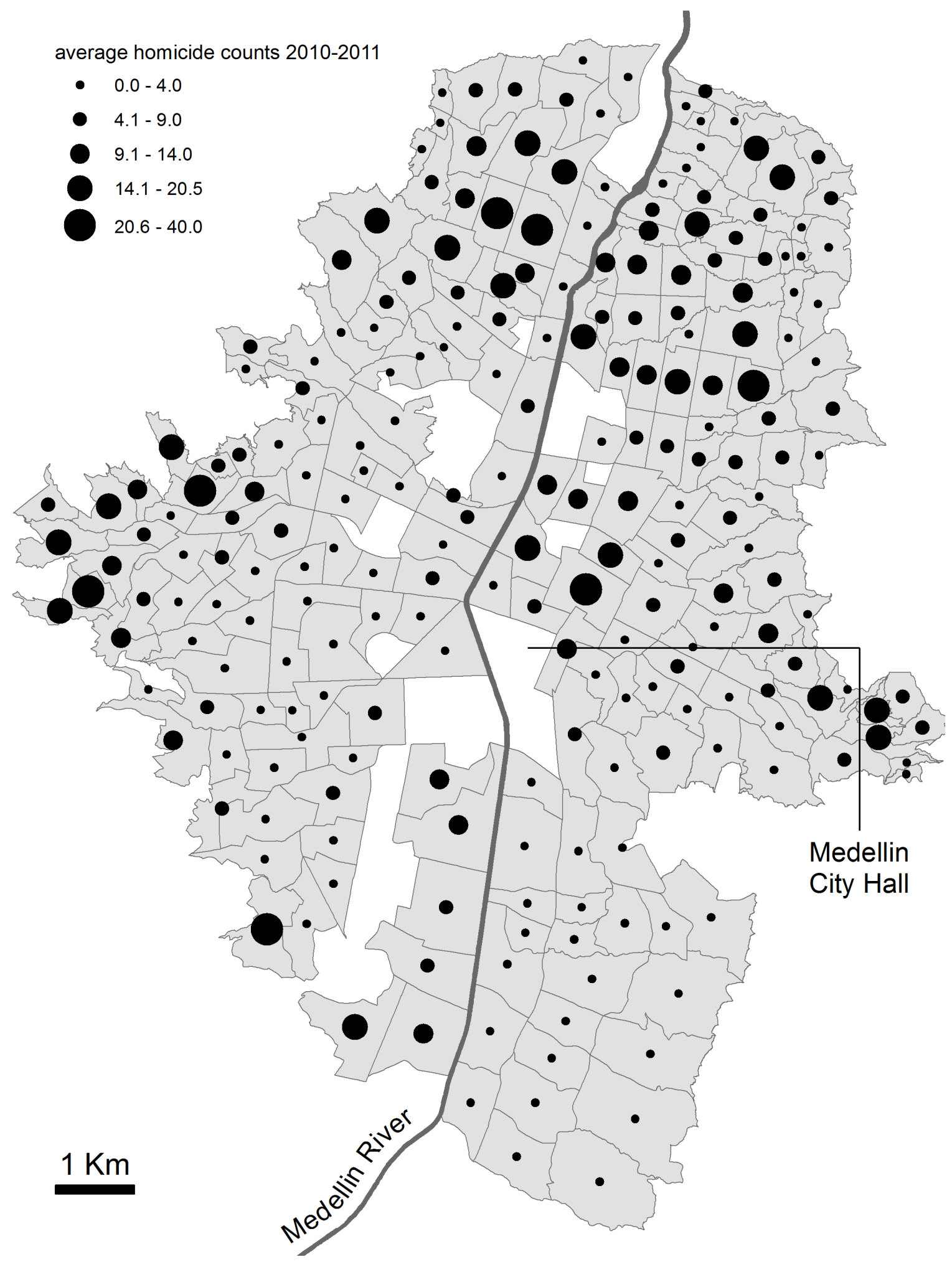


Figure 2. Average homicide counts for the years 2010 and 2011 at the administrative neighborhood level. Data source: SISC.

\subsection{Spatial unit of analysis}

Medellin has two levels of urban administrative units: communes and neighborhoods. Socioeconomic variables and indicators from the 2009 Quality of Life Survey were reported at the commune level. Two main drawbacks arise when using these units: they are too large to study the spatial patterns of intra-urban variations in socioeconomic conditions, and the statistical inference based on these units may be affected by aggregation problems such as the ecological fallacy (Robinson, 1950) and aggregation bias (Amrhein \& Flowerdew, 1992; Fotheringham \& Wong, 1991; J. H. P. Paelinck \& Klaassen, 1979; Jean H.P. Paelinck, 2000). The average number of surveyed households by neighborhood in 2009 was $86 \pm 54$, with values ranging from 2 to 277 , and 28 neighborhoods had fewer than 30 surveyed households; thus, the Medellin's administrative neighborhoods are unsuitable as spatial units of analysis because of the lack of statistical validity.

A proper alternative is to use analytical regions, spatial units that fulfill specific criteria that are relevant to the phenomena under study: size, shape, or attribute homogeneity (Juan Carlos Duque, Artís, \& Ramos, 2006; Weeks, Hill, Stow, Getis, \& Fugate, 2007). Analytical regions were delineated by grouping the administrative neighborhoods using the Max-PRegions algorithm in ClusterPy software (Juan C. Duque, Dev, Betancourt, \& Franco, 2011; Juan Carlos Duque, Anselin, \& Rey, 2012). ${ }^{1}$ This process has been used in previous research on the urban spatial structure and spatial dynamics of major U.S. metropolitan areas (Arribas-Bel \& Schmidt, 2013; Rey et al., 2011), pediatric mortality in Brazil (Leyk, Norlund, \& Nuckols, 2012), interregional inequality in Mexico (Rey \& Sastré-Gutiérrez, 2010), intraurban inequalities in Accra, Ghana (Stow, Lippitt, \& Weeks, 2010; Weeks, Hill, Stow, Getis, \& Fugate, 2006; Weeks et al., 2007), and intra-urban poverty in Medellin, Colombia (Juan C. Duque et al., 2013). Regionalization can reduce the spurious spatial autocorrelation that is present when analyzing smaller administrative spatial units (Weeks et al., 2007).

The Max-p-Regions seeks to aggregate $n$ areas into the maximum amount of spatially contiguous regions, such that each region satisfies a predefined minimum threshold value for some spatially extensive regional attribute (e.g. the number of surveyed households per region). The Max-p-Regions also seeks to minimize intra-regional heterogeneity measured as:

$$
H=\sum_{k=1}^{p} \sum_{\left(i j \in R_{k} \mid i<j\right)} d_{i j}
$$

Where $d_{i j}$ is the multidimensional squared Euclidean distance between areas $i$ and $j$ assigned to the same region $k, R_{k}$. Both objectives, the number of regions and the intraregional heterogeneity, are merged into a single objective function as follows:

\footnotetext{
${ }^{1}$ ClusterPy is an open source library of spatially constrained clustering algorithms that runs in the Python programming language (Juan C. Duque et al., 2011).
} 


$$
\text { Minimize } Z=\left(-\sum_{k=1}^{n} \sum_{i=1}^{n} x_{i}^{k 0}\right) \times 10^{h}+\sum_{i} \sum_{j \mid j>i} d_{i j} t_{i j} \text {. }
$$

With two binary decision variables: $x_{i}^{k 0}=1$ if area $i$ is assigned to region $k$ in order 0 (each region has one and only one area assigned at this order), and $t_{i j}=1$ if areas $i$ and $j$ are assigned to the same region. The first term represents the number of regions and the second term represents the intra-regional heterogeneity. Both terms are merged into a single value in such a way that an increment in the number of regions is preferred over any other solution involving a lower number of regions, and for a given number of regions, the solution with lower intra-regional heterogeneity is preferred. This hierarchy in the elements of the objective function are ensured by multiplying the first term by a scaling factor $10^{h}$, with $h=1+\left\lfloor\log \sum_{i} \sum_{j \mid j>i} d_{i j}\right\rfloor$. In this work, each analytical region was required to meet the following criteria: socioeconomic homogeneity, measured using a wide set of socioeconomic variables from the 2005 National Census, and a minimum of 100 surveyed households in the 2009 Quality of Life Survey as requirement for statistical validity. Homicide rates and socioeconomic variables for the years 2005 and 2009 were computed for the resulting analytical regions.

\subsection{Remote sensing data}

A very high spatial-resolution (VHR) image was used to build a database of variables at the analytical region level. The image was an RGB composition of a Quickbird scene with spatial resolution of $0.60 \mathrm{~m}$ captured in May 2008. VHR imagery allows an accurate classification of urban landscape features. Medellin City Hall Officers of the Sigame Group preprocessed the original Quickbird image using standard procedures. They used the RCPs provided by the distributor and a local DEM to orthorectify the image. Then they did a fusion of the panchromatic band with the multispectral band to produce the pan sharpened natural color RGB composition. For this work, we did not have access to the original image with near infrared (NIR) information, but to this natural color composition with spatial resolution of $0.6 \mathrm{~m}$.

\section{Methods}

\subsection{Image processing}

We applied principal component analysis to summarize the spectral information of the red, green and blue bands into one single band (the first principal component, PC1) and the band ratios red/blue and green/red to enhance the spectral information for a better differentiation of surfaces that reflected red and green. The image-derived variables were grouped into a set of land cover features, a set of structure features and a set of texture features.

Land cover features characterize the composition of an urban scene in terms of three basic land cover types, vegetation, soil, and impervious surfaces, and an additional land cover: clay roofs. Land cover features were obtained through pixel-based supervised classification using the maximum likelihood algorithm in ENVI with the composite image of PC1 and the $\mathrm{red} /$ blue and green/red band ratios (Figure 3). The classification accuracy was assessed using a traditional point- based technique with a reference dataset of randomly selected 
points (a sample of ground truth points was collected and randomly divided into two datasets: $80 \%$ as a classification training set and the other $20 \%$ for accuracy assessment). The overall accuracy of this classification was $95 \%$, with a kappa statistic value of 0.94 . Table 1 shows the confusion matrix for the classification results. The producer's accuracy for vegetation, impervious surfaces, soil and the clay roof classes was over $93 \%$; user accuracy was over $91 \%$ for the vegetation class; over $98 \%$ for the impervious surface and clay roof classes; and approximately $77 \%$ for the soil class. We then calculated the percentage cover of vegetation, impervious surfaces, soil and clay roofs within analytical regions to build the following variables: percent of vegetation, percent of impervious surfaces, percent of soil, percent of clay roof surfaces, percent of impervious surfaces other than clay roofs and the fraction of clay roofs among the impervious surfaces.
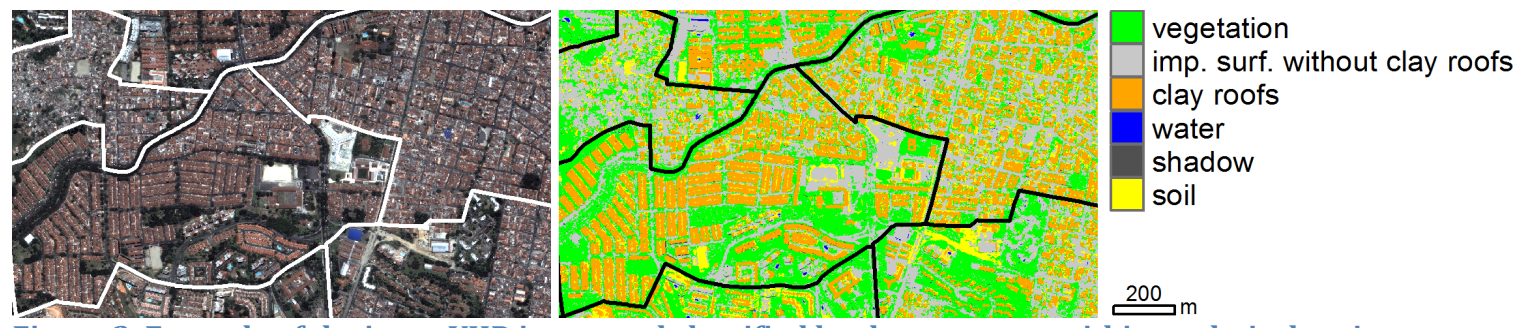

Figure 3. Example of the input VHR image and classified land cover types within analytical regions.

Table 1. Accuracy assessment of the classified image.

\begin{tabular}{|c|c|c|c|c|c|c|c|}
\hline Ground truth & Vegetation & $\begin{array}{c}\text { Imp. } \\
\text { surfaces } \\
\text { without clay } \\
\text { roofs }\end{array}$ & Clay roofs & Water & Shadow & Soil & Total \\
\hline Training samples & 2,952 & 5,636 & 2,920 & 1,732 & 768 & 800 & 14,808 \\
\hline Validation samples & 738 & 1,409 & 730 & 433 & 192 & 200 & 3,702 \\
\hline \multicolumn{8}{|l|}{ Classified as } \\
\hline Vegetation & 712 & 24 & 14 & 0 & 26 & 0 & 776 \\
\hline Imp. surfaces without clay roofs & 10 & 1,356 & 0 & 6 & 1 & 9 & 1,382 \\
\hline Clay roofs & 0 & 0 & 708 & 0 & 0 & 5 & 713 \\
\hline Water & 0 & 0 & 0 & 400 & 0 & 0 & 400 \\
\hline Shadow & 6 & 0 & 0 & 18 & 165 & 0 & 189 \\
\hline Soil & 10 & 29 & 8 & 9 & 0 & 186 & 242 \\
\hline Total & 738 & 1,409 & 730 & 433 & 192 & 200 & \\
\hline Producer Accuracy (\%) & 96.48 & 96.24 & 96.99 & 92.38 & 85.94 & 93.00 & \\
\hline User Accuracy (\%) & 91.75 & 98.12 & 99.29 & 100.00 & 87.30 & 76.86 & \\
\hline Overall classification accuracy (\%) & & 95.27 & & & & & \\
\hline Kappa value & & 0.94 & & & & & \\
\hline
\end{tabular}

We used the PC1 and the analytical region boundaries to extract the structure and texture features using FETEX 2.0.2 These features quantify different aspects of the spatial arrangement of the images intensity values within the analytical regions, and we used them to quantify the differences in the spatial pattern of the urban layout.

\footnotetext{
2 FETEX 2.0 is a free software tool for object-based image analysis that runs on ENVI image processing software and the IDL programming language (Ruiz et al., 2011).
} 
Structure features inform about the spatial arrangement of elements within regions in terms of the randomness or regularity of the distribution of the elements (Balaguer, Ruiz, Hermosilla, \& Recio, 2010; Balaguer-Beser, Ruiz, Hermosilla, \& Recio, 2013; Ruiz, Recio, Fernández-Sarría, \& Hermosilla, 2011); structure features are calculated in FETEX 2.0 using the experimental semivariogram approach. The semivariogram quantifies the spatial associations of the intensity values, measures the degree of spatial correlation between different pixels in an image and is a suitable tool for characterizing spatial patterns (Ruiz et al., 2011). FETEX 2.0 obtains the experimental semivariogram of each polygon by computing the mean of the semivariogram calculated in six different directions, from $0^{\circ}$ to $150^{\circ}$ with step increments of $30^{\circ}$; then, each semivariogram curve is smoothed using a Gaussian filter to reduce experimental fluctuations (Ruiz et al., 2011). Structure features extracted from the semivariogram are based on a zonal analysis defined by a set of singular points on the semivariogram, such as the first maximum, the first minimum, and the second maximum (Ruiz et al., 2011). ${ }^{3}$

Texture features quantify the spatial distribution of intensity values in the image and provide information about contrast, uniformity, roughness, etc. (Baraldi \& Parmiggiani, 1995; Haralick, Shanmugam, \& Dinstein, 1973). FETEX 2.0 calculates the grey-level cooccurrence matrix (GLCM) and the histogram of pixel values inside each polygon for texture feature extraction. The GLCM tabulates the frequency of one gray tone appearing in a specified spatial relationship with another gray tone within the analyzed polygon (Baraldi \& Parmiggiani, 1995). FETEX 2.0 uses the GLCM to calculate a set of variables that are widely used in image processing: uniformity, entropy, contrast, inverse difference moment (IDM), covariance, variance, and correlation (Haralick et al., 1973). The kurtosis and skewness features are based on the histogram of the pixel values inside the polygon. The edgeness factor is another feature that represents the density of edges present in a region (Sutton \& Hall, 1972), and the mean and standard deviation of the edgeness factor (MEAN EDG, STDEV EDG) are also computed within this set of features (Ruiz et al., 2011). Table 2 shows the list of remote sensing variables used in this paper.

Table 2. Description and summary statistics of the remote sensing derived variables at the analytical region level $(\mathrm{N}=136)$.

\begin{tabular}{|c|c|c|c|c|}
\hline Group & Variable name & Description & Mean & Std. Dev. \\
\hline Land & P.VEG & Percentage of vegetation cover & 36.01 & 13.59 \\
\hline \multirow[t]{5}{*}{$\begin{array}{l}\text { cover } \\
\text { features }\end{array}$} & P.IMP.SURF & $\begin{array}{l}\text { Percentage of impervious surface cover including clay } \\
\text { roofs cover }\end{array}$ & 54.73 & 13.30 \\
\hline & P.SOIL & Percentage of bare soil cover & 8.13 & 2.66 \\
\hline & P.CLAY.ROOFS & Percentage of clay roof cover & 13.30 & 9.23 \\
\hline & P.OTHER.IMP.S & $\begin{array}{l}\text { Percentage of impervious surfaces without clay roof } \\
\text { cover }\end{array}$ & 41.43 & 14.39 \\
\hline & F.CLAYR.IMPS & $\begin{array}{l}\text { Fraction of clay roof cover within the impervious surface } \\
\text { cover }\end{array}$ & 0.25 & 0.16 \\
\hline \multirow{6}{*}{$\begin{array}{l}\text { Structure } \\
\text { features }\end{array}$} & RVF & Ratio variance at first lag & 12.26 & 2.94 \\
\hline & RSF & $\begin{array}{l}\text { Ratio between semivariance values at second and first } \\
\text { lag }\end{array}$ & 1.80 & 0.02 \\
\hline & FDO & First derivative near the origin & 117.68 & 20.09 \\
\hline & SDT & Second derivative at third lag & 15.33 & 3.18 \\
\hline & MFM & $\begin{array}{l}\text { Mean of the semivariogram values up to the first } \\
\text { maximum }\end{array}$ & 828.19 & 129.96 \\
\hline & VFM & Variance of the semivariogram values up to the first & 1.45 & 0.22 \\
\hline
\end{tabular}

\footnotetext{
${ }^{3}$ For a full description of these features see Balaguer et al. (2010), Balaguer-Beser et al. (2013) and Ruiz et al. (2011).
} 


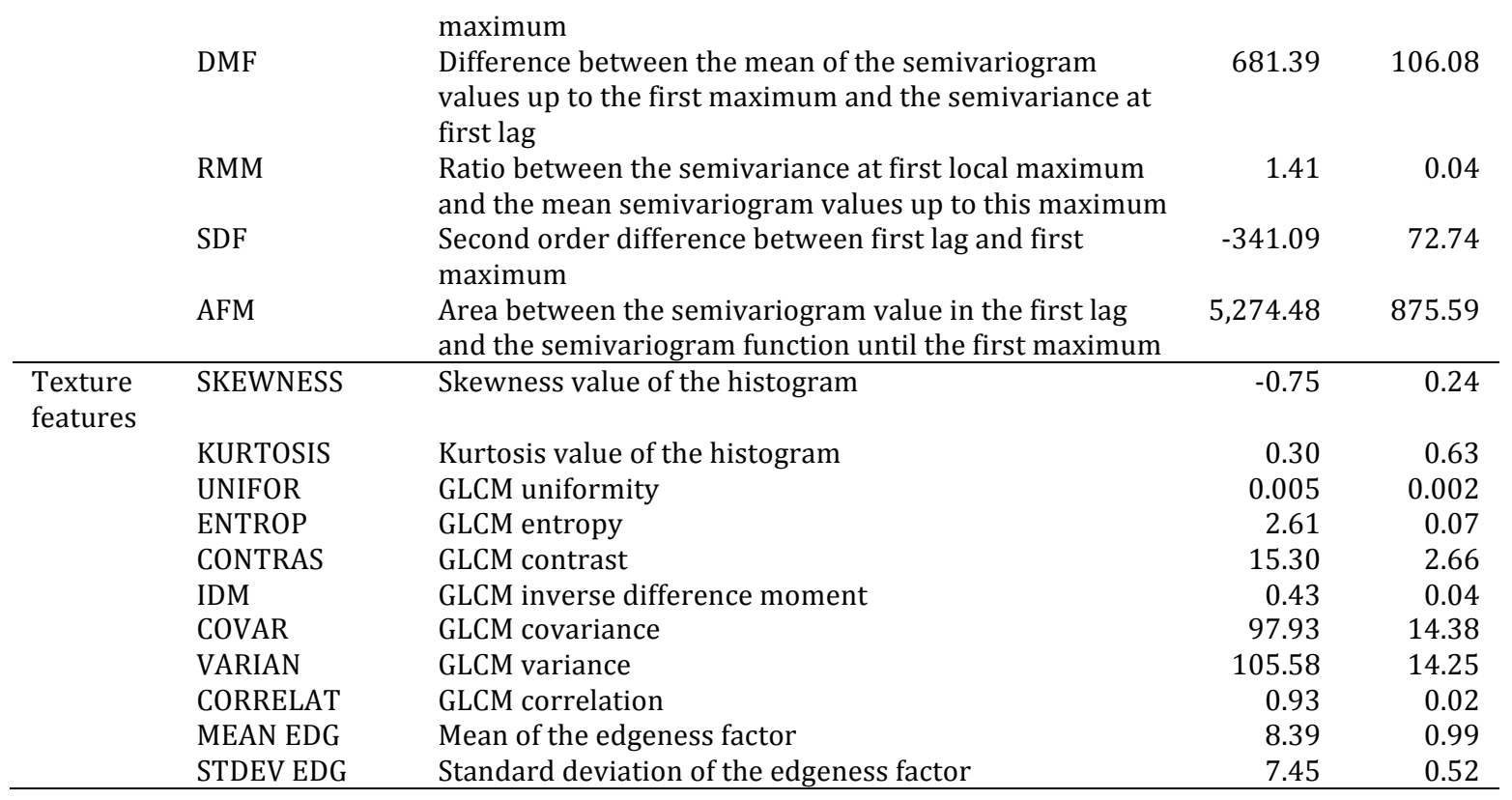

\subsection{Econometric analysis}

We built an econometric model of homicide rates as a function of socioeconomic factors to assess if the remote sensing variables added to the model were significant and had the expected sign. The dependent variable was the average homicide rate per 100,000 people for the years 2010 and 2011 at the analytical region level, and the predictors were socioeconomic variables from the years 2005 and 2009 related to the homicide rate at the intra-urban level according to the literature. We used this time lag of one year between the independent variables and the dependent variable to avoid endogeneity effects. Figure 4 outlines the methodology.

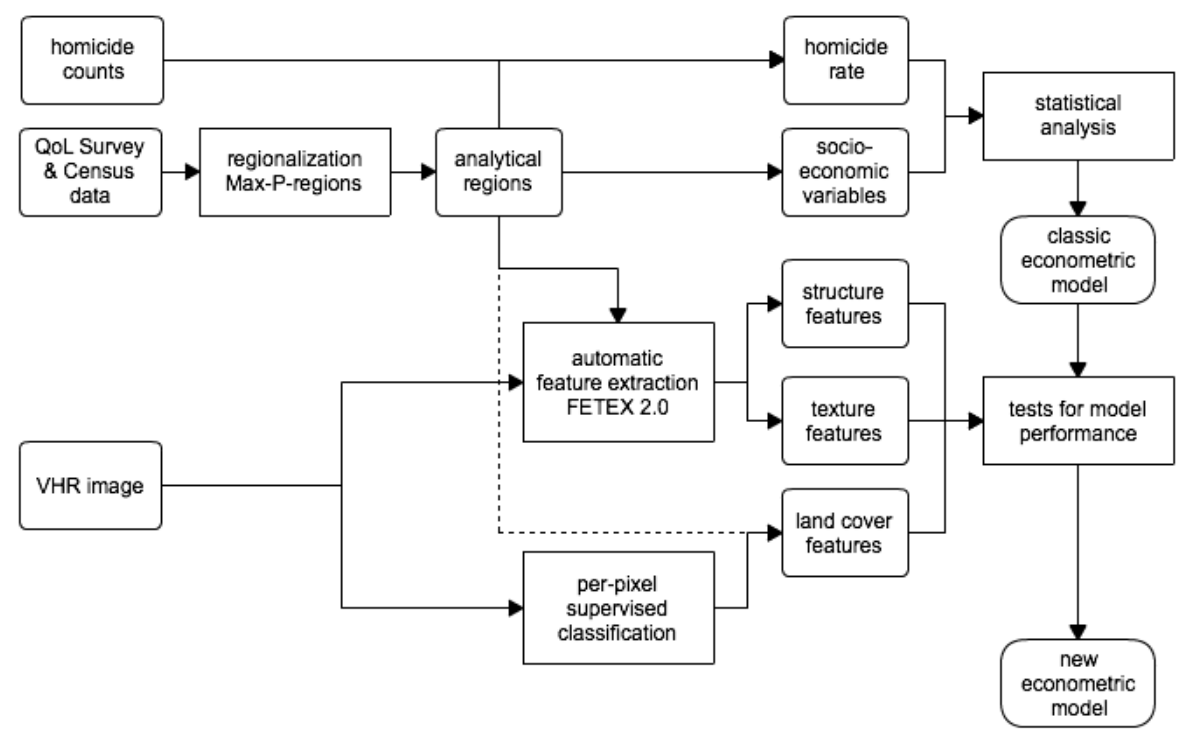

Figure 4. Main steps of modeling the homicide rate as a function of socioeconomic and remote sensing variables at the analytical region level. 
Previous research related the concentration of interpersonal violence to neighborhoods characterized by poverty, the segregation of minority groups, and the presence of singleparent families (Morenoff, Sampson, \& Raudenbush, 2001). The presence of young males, income inequality, unemployment, concentrated disadvantage, population density, residential instability, concentrated immigration, family disruption, educational attainment and ethnicity have been used in homicide econometric models in different cities around the world (Browning et al., 2010; DeFronzo, 1984; Kawachi, Kennedy, \& Wilkinson, 1999; Kennedy, Kawachi, Prothrow-Stith, Lochner, \& Gupta, 1998; Menezes, Silveira-Neto, Monteiro, \& Ratton, 2013; Morenoff et al., 2001; Wang \& Arnold, 2008; Y. Ye, Zhang, Liu, \& $\mathrm{Wu}, 2011)$. However, it is possible that some of the variables that explain intra-urban variations in the homicide rate in one city do not perform in the same way in different cities.

Ethnicity and immigration are of little importance in Medellin because the ethnic composition is very homogeneous throughout the city, with more than $90 \%$ of its inhabitants considering themselves white descendants, and these variables show little spatial variation across the city. In Colombia, the homicide rates at the city level have been related to the variables discussed above as well as to the justice systems inefficacy, the war on drugs, and the presence of illegal armed groups and gangs (Giraldo Ramírez, 2010; Levitt \& Rubio, 2000; Medina \& Martínez, 2003; Medina, Posso, \& Tamayo, 2011; Sánchez Torres \& Núñez Méndez, 2001). The justice systems inefficacy and the war on drugs cannot be taken into account because they are constants throughout the city. Medina et al. (2011) reported that $75 \%$ of murder victims in Medellin in the first six months of 2009 were assassinated in their own neighborhoods, which is related to the territorial control struggle between gangs. The presence of gangs does show intra-urban variations and was considered in the econometric model of the homicide rate at the intra-urban level in Medellin. The estimated model has the following form:

$$
Y=c+X \beta+\epsilon
$$

Where $Y$ is an $n$ by 1 vector of the dependent variable: the average homicide rate per 100,000 people for the years 2010 and 2011; $X$ is an $n$ by $k$ matrix of observations on explanatory variables from the years 2005 and 2009, with an associated $k$ by 1 vector of regression coefficients $(\beta)$; and $\epsilon$ is an $n$ by 1 vector of error terms. We built the classic model according to the following apriori hypothesis. All variables were computed at the analytical region level from the 2009 Quality of Life Survey, with the exception of population density, which was computed from the 2005 Census:

- Downtown (DOWNTOWN): dummy variable equal to 1 for the downtown area of the city. The homicide rates in the downtown area were expected to be unusually high because of the high floating population that is not recorded as living downtown in the Census.

- Population density (POP.DENS): expressed as people per hectare. A positive association was expected between population density and the homicide rate.

- Gang presence (GANGS): measured as the fraction of households that had been victims of criminal gangs. High gang presence in an area was expected to be related to high homicide rates.

- Residential instability (NO.OWNERS): measured as the fraction of households that did not own the house where they lived. Areas with high residential instability will 
have less social cohesion and more anonymity, which was expected to be associated with high homicide rates.

- Income inequality (GINI.INC): measured using the Gini coefficient of income, which was calculated from household income data within analytical regions. A positive association was expected.

- Young males (YOUNG.MALES): measured as the fraction of males between 20 and 24 years old as a proxy for the presence of young males in the neighborhood. The presence of young males was expected to have a positive association with the homicide rate.

- Family disruption (DIVORCED): measured as the fraction of households with divorced parents. A positive relationship with the homicide rate was expected.

- Unemployment (UNEMPL): computed as the fraction of unemployed people in the neighbor- hood. High unemployment was expected to be related to high homicide rates.

Table 3 presents the summary statistics of these variables and Figure 5 shows their corresponding maps at the analytical region level. The modeling process was implemented in OpenGeoda software (Anselin, Syabri, \& Kho, 2006). We ran an ordinary least squares (OLS) regression and the diagnostics for spatial dependence using a Rook type contiguity matrix with row-standardized weights. We followed the hybrid specification search strategy based on robust Lagrange multiplier tests because the standard versions were both significant (Anselin, 2005; Florax, Folmer, \& Rey, 2003). The robust Lagrange multiplier tests indicated the presence of residual spatial autocorrelation that had to be adjusted using a spatial error model. The results of the log likelihood ratio test, as well as the Akaike information criterion and Schwarz criterion values, showed the superiority of the spatially adjusted regression over its OLS counterpart, and according to Anselin (2005), in finite samples, the Wald test (W), the likelihood ratio test (LR) and the Lagrange multiplier test (LM) based on OLS residuals should follow the order: $W>L R>L M$, as they did in this model. Table 4 shows the information from both models.

Table 3. Summary statistics of the exogenous socioeconomic variables $(\mathrm{N}=136)$.

\begin{tabular}{lll}
\hline Variable & Mean & Std. Dev. \\
\hline POP.DENS & 301.46 & 152.16 \\
GANGS & 0.11 & 0.13 \\
NO.OWNERS & 0.40 & 0.09 \\
GINI.INC & 0.43 & 0.12 \\
YOUNG.MALES & 0.10 & 0.02 \\
DIVORCED & 0.11 & 0.03 \\
UNEMPL & 0.07 & 0.03 \\
\hline
\end{tabular}



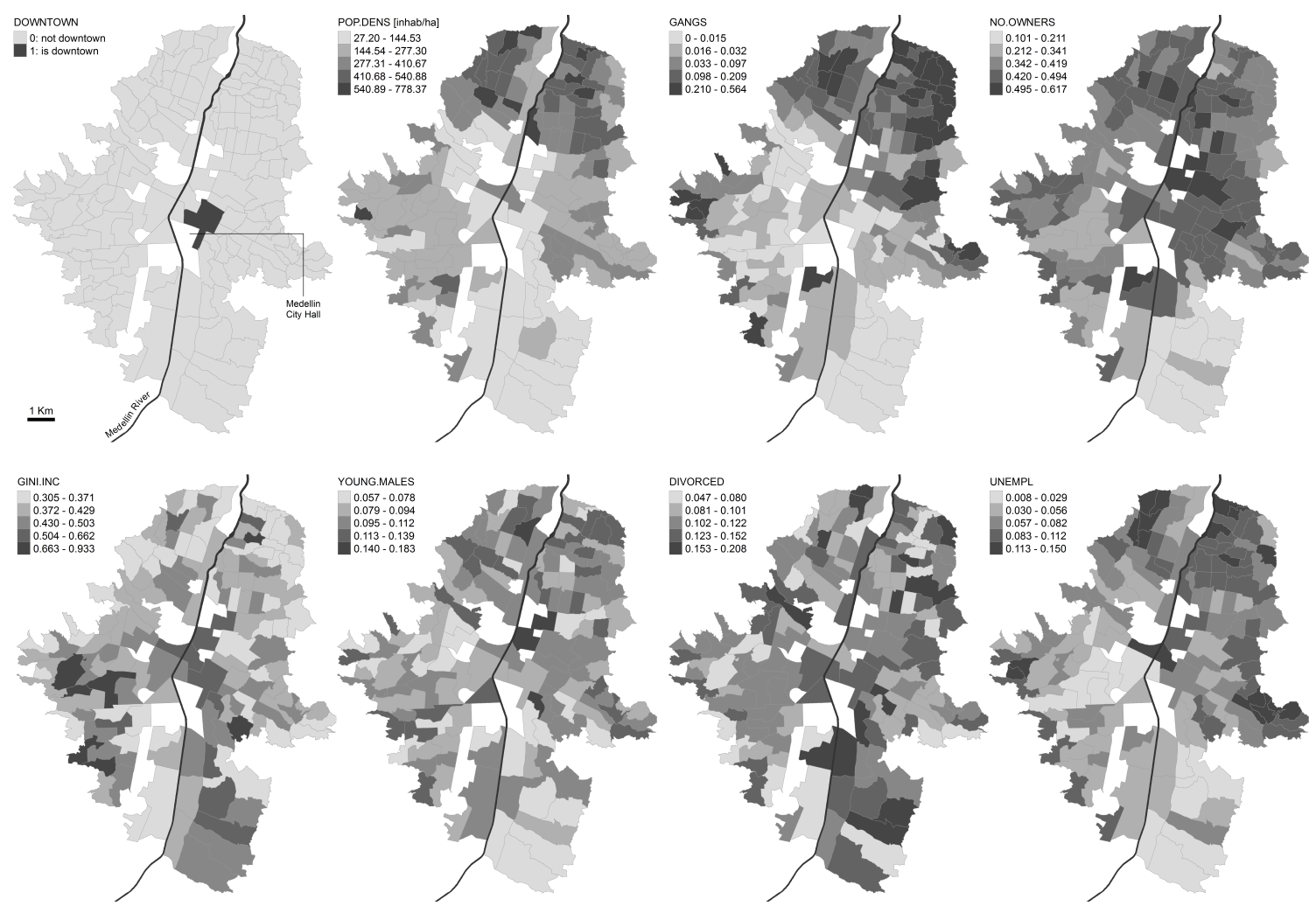

Figure 5. Choropleth maps of the socioeconomic variables included in the model specification of the average homicide rate per 100,000 people $(2010$ - 2011) in Medellin at the analytical region level. All variables classified into intervals using the Natural Breaks method.

Table 4. Classic model specification of the average homicide rate per 100,000 people $(2010$ - 2011$)$ as a function of the socioeconomic variables. Coefficients and significance levels for the OLS and spatial error models. Spatial unit: analytical regions. $\mathrm{N}=136$.

\begin{tabular}{lcc}
\hline Exogenous variables & OLS model & Spatial Error Model \\
\hline Constant & -18.4223 & -1.8289 \\
DOWNTOWN & $410.4631^{* * *}$ & $423.0517^{* * *}$ \\
POP.DENS & $0.1419^{* * *}$ & $-0.1330^{* * *}$ \\
GANGS & $95.7671^{* *}$ & $51.8867^{*}$ \\
NO.OWNERS & $249.5371^{* * *}$ & $245.0647^{* * *}$ \\
GINI.INC & -50.7756 & $-51.8295^{* *}$ \\
YOUNG.MALES & 201.2657 & 158.1371 \\
DIVORCED & 102.2078 & 112.8527 \\
UNEMPL & 228.0302 & 137.8414 \\
Lambda & & $0.6907^{* * *}$ \\
$R^{2}$ & 0.51 & 0.71 \\
Adjusted $R^{2}$ & 0.48 & \\
Multicollinearity Condition Number & 24.88 & \\
Koenker-Bassett test & 7.24 & \\
Diagnostics for spatial dependence: & & \\
Lagrange multiplier - lag & & \\
Robust LM - lag & $36.4435^{* * *}$ & \\
Lagrange multiplier - error & 0.4038 & \\
Robust LM - error & $47.8951^{* * *}$ & \\
& $11.8554^{* * *}$ & \\
Wald test & & 107.37 \\
\hline
\end{tabular}




\begin{tabular}{lcc}
\hline W > LR > LM & yes \\
Akaike information criterion & $1,453.29$ & $1,402.92$ \\
Schwarz criterion & $1,479.51$ & $1,429.13$ \\
Log Likelihood & -717.65 & -692.46 \\
\hline Note: Statistical significance is at the 1, 5, and 10\% levels as indicated by ***,*, and * respectively.
\end{tabular}

Note: Statistical significance is at the 1,5 , and $10 \%$ levels as indicated by ${ }^{* * *},{ }^{* *}$, and ${ }^{*}$ respectively.

We ran spatially adjusted regressions with the socioeconomic variables plus one remote sensing variable at a time to assess which included variables were significant without compromising model performance. We considered that model performance was not compromised if the new specification fulfilled these conditions: the included variable had to be significant in the model specification, the inclusion of the variable could not increase the models multicollinearity (otherwise, the information it contributed to the model could have already been accounted for with the socioeconomic variables), and the information criteria (Akaike or Schwarz) and the likelihood ratio test had to indicate the improved fit of the new model over the classic specification. Table 5 summarizes the results of this exercise: an asterisk shows that the included variable was statistically significant at the $5 \%$ level in the spatial error model, that multicollinearity was not a serious concern, and that the log likelihood ratio test, the Akaike information criterion or the Schwarz criterion indicated improved fit over the classic model.

Table 5. Summary of the results of including the remote sensing derived variables in the classic spatial error model. An asterisk indicates that including the variable fulfilled the criteria.

\begin{tabular}{|c|c|c|c|c|c|c|}
\hline Group & Variable & Significant & Multicollinearity & $\begin{array}{c}\text { LL Ratio } \\
\text { test }\end{array}$ & $\begin{array}{c}\text { Akaike inf. } \\
\text { c. }\end{array}$ & Schwarz c. \\
\hline \multirow{6}{*}{$\begin{array}{l}\text { Land cover } \\
\text { features }\end{array}$} & P.VEG & & & & & \\
\hline & P.IMP.SURF & & $*$ & & & \\
\hline & P.SOIL & & * & & & \\
\hline & P.CLAY.ROOFS & & $*$ & & & \\
\hline & P.OTHER.IMP.S & * & $*$ & $*$ & $*$ & $*$ \\
\hline & F.CLAYR.IMPS & * & $*$ & $*$ & $*$ & $*$ \\
\hline \multirow{10}{*}{$\begin{array}{l}\text { Structure } \\
\text { features }\end{array}$} & RVF & $*$ & & * & * & \\
\hline & RSF & & & & & \\
\hline & FDO & $*$ & & $*$ & $*$ & \\
\hline & SDT & * & $*$ & $*$ & $*$ & \\
\hline & MFM & $*$ & & $*$ & $*$ & $*$ \\
\hline & VFM & & & & & \\
\hline & $\mathrm{DMF}$ & $*$ & & $*$ & $*$ & $*$ \\
\hline & RMM & & & & & \\
\hline & SDF & $*$ & $*$ & $*$ & * & \\
\hline & AFM & $*$ & & $*$ & $*$ & $*$ \\
\hline \multirow{11}{*}{$\begin{array}{l}\text { Texture } \\
\text { features }\end{array}$} & SKEWNESS & & & & & \\
\hline & KURTOSIS & & $*$ & & & \\
\hline & UNIFOR & $*$ & $*$ & $*$ & $*$ & $*$ \\
\hline & ENTROP & $*$ & & $*$ & $*$ & \\
\hline & CONTRAS & * & & & $*$ & \\
\hline & IDM & $*$ & & $*$ & $*$ & \\
\hline & COVAR & & & & & \\
\hline & VARIAN & & & & & \\
\hline & CORRELAT & & & & $*$ & \\
\hline & MEAN EDG & * & & $*$ & $*$ & \\
\hline & STDEV EDG & & & & $*$ & \\
\hline
\end{tabular}

The remote sensing variables whose inclusion fulfilled all conditions were P.OTHER.IMP.S and F.CLAYR.IMPS from the land cover features group; SDT and SDF from the structure group; and UNIFOR from the texture group. These variables informed about the land cover 
composition, the spatial arrangement of the urban layouts elements (structure group), and the uniformity of the urban fabric within the analytical regions (texture group). Table 6 shows the corresponding spatial error models.

Table 6. Spatial error models of the average homicide rate per 100,000 people (2010 - 2011) as a function of the socioeconomic variables and one remote sensing variable. Spatial unit: analytical regions. $\mathbf{N}=136$. Models 1 and 2 include socioeconomic variables plus one land cover variable at a time. Models 3 and 4 include socioeconomic variables plus one structure variable at a time. Model 5 includes socioeconomic variables plus one texture variable.

\begin{tabular}{|c|c|c|c|c|c|}
\hline Exogenous variables & Model 1 & Model 2 & Model 3 & Model 4 & Model 5 \\
\hline Constant & -8.3806 & 33.2173 & -26.5559 & -25.0011 & 26.5149 \\
\hline DOWNTOWN & $402.0680^{* * *}$ & $412.7394^{* * *}$ & $419.9667^{* * *}$ & $411.4869^{* * *}$ & $419.3412^{* * *}$ \\
\hline POP.DENS & $-0.1700^{* * *}$ & $-0.1508^{* * *}$ & $-0.1433^{* * *}$ & $-0.1702^{* * *}$ & $-0.1487^{* * *}$ \\
\hline GANGS & $59.0273^{* *}$ & 32.3126 & 48.9399 & $57.0203^{* *}$ & $51.3281^{*}$ \\
\hline NO.OWNERS & $223.6354^{* * *}$ & $259.6264^{* * *}$ & $241.1003^{* * *}$ & $217.4753^{* * *}$ & $211.6481^{* * *}$ \\
\hline GINI.INC & $-49.5049 * *$ & -42.1245 & $-59.3078^{* *}$ & $-55.7996^{* *}$ & $-54.4743^{* *}$ \\
\hline YOUNG.MALES & 91.4376 & 97.9944 & 157.3962 & 140.8751 & 152.4899 \\
\hline DIVORCED & 96.1949 & 82.9640 & 88.6220 & 112.6263 & $166.3085^{*}$ \\
\hline UNEMPL & 105.9465 & -3.1900 & 90.3745 & 149.1204 & $237.9309 *$ \\
\hline P.OTHER.IMP.S & $0.8646^{* * *}$ & & & & \\
\hline F.CLAYR.IMPS & & $-72.9792^{* *}$ & & & \\
\hline SDT & & & $2.5733^{* *}$ & & \\
\hline SDF & & & & $-0.1400^{* *}$ & \\
\hline UNIFOR & & & & & $-4,271.1080^{* *}$ \\
\hline Lambda & $0.7021^{* * *}$ & $0.7005^{* * *}$ & $0.7091^{* * *}$ & $0.7008^{* * *}$ & $0.6972^{* * *}$ \\
\hline$R^{2}$ & 0.72 & 0.72 & 0.72 & 0.72 & 0.72 \\
\hline $\mathrm{W}>\mathrm{LR}>\mathrm{LM}$ & yes & yes & yes & yes & yes \\
\hline Akaike inf. criterion & $1,398.72$ & $1,399.48$ & $1,400.77$ & $1,400.46$ & $1,399.97$ \\
\hline Schwarz criterion & $1,427.85$ & $1,428.61$ & $1,429.89$ & $1,429.59$ & $1,429.10$ \\
\hline Log Likelihood & -689.36 & -689.74 & -690.38 & -690.23 & -689.99 \\
\hline
\end{tabular}

Note: Statistical significance is at the 1,5 , and $10 \%$ levels as indicated by ${ }^{* * *}, * *$, and ${ }^{*}$ respectively.

We then tested the inclusion of combinations of two remote sensing variables from the previous selection in the classic model to assess whether they captured complementary information about the urban fabric or informed about similar aspects. The three combinations of variables that showed an improvement over the classic model are presented in Table 7. A discussion of these results is presented in the next section.

Table 7. Spatial error models of the average homicide rate per 100,000 people (2010 - 2011) as a function of the socioeconomic variables and two remote sensing variables. Spatial unit: analytical regions. $\mathrm{N}=136$. Models 6 and 7 include socioeconomic variables plus one land cover variable and one texture variable. Model 8 includes socioeconomic variables plus one land cover variable and one structure variable.

\begin{tabular}{lccc}
\hline Exogenous variables & Model 6 & Model 7 & Model 8 \\
\hline Constant & 17.7203 & $69.8542^{* *}$ & 10.2641 \\
DOWNTOWN & $400.1827^{* * *}$ & $407.1254^{* * *}$ & $400.0821^{* * *}$ \\
POP.DENS & $-0.1841^{* * *}$ & $-0.1709^{* * *}$ & $-0.1909^{* * *}$ \\
GANGS & $58.1735^{*}$ & 29.3208 & 37.0499 \\
NO.OWNERS & $194.8035^{* * *}$ & $223.3692^{* * *}$ & $231.1741^{* * *}$ \\
GINI.INC & $-52.0982^{* *}$ & $-43.9087^{*}$ & $-45.9163^{*}$ \\
YOUNG.MALES & 91.1029 & 83.8527 & 76.9909 \\
DIVORCED & 145.9673 & 140.0600 & 81.4866 \\
UNEMPL & 199.3559 & 93.3247 & 1.9449
\end{tabular}




\begin{tabular}{|c|c|c|c|}
\hline P.OTHER.IMP.S & $0.8022^{* *}$ & & \\
\hline F.CLAYR.IMPS & & $-82.2869 * * *$ & $-76.4102^{* * *}$ \\
\hline SDF & & & $-0.1481^{* *}$ \\
\hline UNIFOR & $-3,873.1150 * *$ & $-4,859.0850^{* * *}$ & \\
\hline Lambda & $0.7056^{* * *}$ & $0.7084^{* * *}$ & $0.7114^{* * *}$ \\
\hline$R^{2}$ & 0.73 & 0.73 & 0.73 \\
\hline $\mathrm{W}>\mathrm{LR}>\mathrm{LM}$ & yes & yes & yes \\
\hline Akaike inf. criterion & $1,396.48$ & $1,394.81$ & $1,396.24$ \\
\hline Schwarz criterion & $1,428.52$ & $1,426.85$ & $1,428.28$ \\
\hline Log Likelihood & -687.24 & -686.40 & -687.12 \\
\hline
\end{tabular}

\section{Discussion}

The implemented spatial error models (Table 4, Table 6, and Table 7) correspond to a spatial autoregressive (SAR) process (Anselin, 2005), and the highly significant spatial error coefficient (Lambda) values indicate that the spatial effects were properly accounted for in these spatial error models. The modeled spatial interaction implies that each error term was correlated with each other error term in the system, but the magnitude of the correlation decayed with distance. The error terms in the model were considered "ignored" or "unmeasurable" effects, and for the SAR specification, this means that if there were an unmeasurable neighborhood effect, the change in this effect in one location would affect all of the locations in the system following a distance decay effect (Anselin et al., 2000).

The coefficients of the classic model (Table 4) indicate that the homicide rates in Medellin were positively related to the presence of gangs in a neighborhood (measured as the fraction of households that had been victims of gangs), the fraction of non-owner households (proxy for residential instability), the fraction of young males, the fraction of households with divorced parents and the fraction of unemployed people. These findings are as expected and are supported by social disorganization theory (Cullen \& Agnew, 2011; Shaw \& McKay, 1942; Stark, 1987). The rates were negatively related to population density and to the Gini index of income within the analytical region, a result that is contrary to those from a previously reported model for Recife, Brazil (Menezes et al., 2013). In Medellin, the Gini index of income can be taken as a proxy of social mix within analytical regions because income is the most important factor for separating social groups in this city. This result indicates that the presence of different income groups in the same neighborhood could act as a deterrent for this type of criminal behavior in this city. Although empirical evidence about social mix and crime outcomes is complex and ambiguous (Atkinson, 2005), this finding is in agreement with reports of reduced crime rates in urban areas that shifted from public housing to mixed-income neighborhoods in the US (Holin, Buron, Locke, \& Cortes, 2003; Popkin et al., 2004).

The negative association between the average homicide rate and the population density in Medellin also contradicted the conventional belief that the relationship should be positive. The same finding was reported for Chicago by Morenoff et al. (2001) and was explained by the depopulation of the most devastated and poorest areas of the city, which also showed high homicide rates. Cole and Marroquín Gramajo (2009) also reported a negative association between homicide rates and population density in a cross-sectional study at the country level. They found that the effect of population density on homicide rates was 
ambiguous at best, and they highlighted the fact that although many theorists expect high density to be associated with high crime rates, low crime rates are found in both high- and low-density societies. In Medellin, the highest homicide rates occurred in neighborhoods with medium population density.

The associations with the socioeconomic factors remained the same when the remote sensing variables were added to the classic model, with the exception of unemployment, which changed when F.CLAYR.IMPS was included (Table 6, Model 2; and Table 7, Model 7 and Model 8). Roofing materials and styles have been seen as a reflection of the wealth and power of dwelling owners since ancient times (Fiumi, 2012), and clay roofs are more expensive to install and maintain than are other common roofing materials such as zinc or asbestos. In Medellin, the most deprived neighborhoods, where clay roofs are uncommon, showed the highest unemployment rates. This variable could be a proxy for urban poverty, which is in agreement with previously reported associations between poverty and homicide at the intra-urban level (Browning et al., 2010; Sparks, 2011; X. Ye \& Wu, 2011) and is also supported by social disorganization theory concepts.

Previous works have reported significant relationships between measures of vegetation abundance and crime rates in a number of US cities: Chicago, Illinois (Kuo \& Sullivan, 2001); Portland, Oregon (Donovan \& Prestemon, 2012); Baltimore, Maryland (Troy et al., 2012); and Philadelphia, Pennsylvania (Wolfe \& Mennis, 2012). The percentage of vegetation cover was not significant when it was added to the classic model, which indicates that there was no significant relationship with the homicide rates in Medellin. The best-performing variable from the land cover group was P.OTHER.IMP.S (Table 6, Model 1; and Table 7, Model 6), with a positive association with homicide rates: the average homicide rates tended to be higher in areas with higher percentages of impervious surfaces other than clay roof cover.

The best-performing structure and texture variables were SDT and SDF from the structure group (Table 6, Models 3 and Model 4; and Table 7, Model 8) and UNIFOR from the texture group (Table 6, Model 5; and Table 7, Model 6 and Model 7). The structure variable SDT provides information on the concavity level of the semivariogram at short distances, corresponding to the heterogeneity of the image objects (Balaguer et al., 2010). The SDT value increased as the image objects became more heterogeneous at short distances, i.e., where the presence of small dwellings with different roofing materials was common and the absence of homogeneous open spaces and wide roads was the rule. High SDT values were present in unplanned neighborhoods with few or no open spaces, narrow roads and irregular street networks. The association with the homicide rate was positive, which is in agreement with the CPTED concept in the sense that crowded and cluttered urban layouts are associated with higher crime outcomes.

SDF informs about the semivariogram curvature in the interval between its first lag and its first maximum, and it represents the low-frequency values in the image (Balaguer et al., 2010). SDF informs about the spatial arrangement of the elements at short distances and provides another means of quantifying the homogeneity of the urban layouts spatial pattern. Higher SDF values were associated with regions that had open spaces, wide avenues or large industrial facilities. SDF showed a negative association with homicide rates. 
The texture variable UNIFOR (uniformity) is also a measure of homogeneity in the image (Haralick et al., 1973), and high uniformity values occurred when the intensity values within analytical regions were mostly similar. The association of image uniformity with homicide rates was negative, indicating that more uniform and homogeneous urban layouts were associated with low average homicide rates.

The fraction of clay roof cover within the impervious surface cover and uniformity was the best-performing combination of remote sensing variables (Table 7, Model 7), as indicated by the Akaike information criterion, the Schwarz criterion and the log likelihood ratio test. When these two variables were included in the model at the same time, the associations of the other socioeconomic variables with the homicide rates remained the same as in the classic model specification, which means that this combination of variables added to the model by accounting for complementary information about the urban layouts composition and spatial pattern that also affected the homicide rates. Figure 6 shows the analytical region maps of the remote sensing variables included in the models. Figure 7 shows square image tiles of 500 meters with the corresponding values for the remote sensing variables to illustrate the differences in urban landscapes corresponding to different values of these variables.

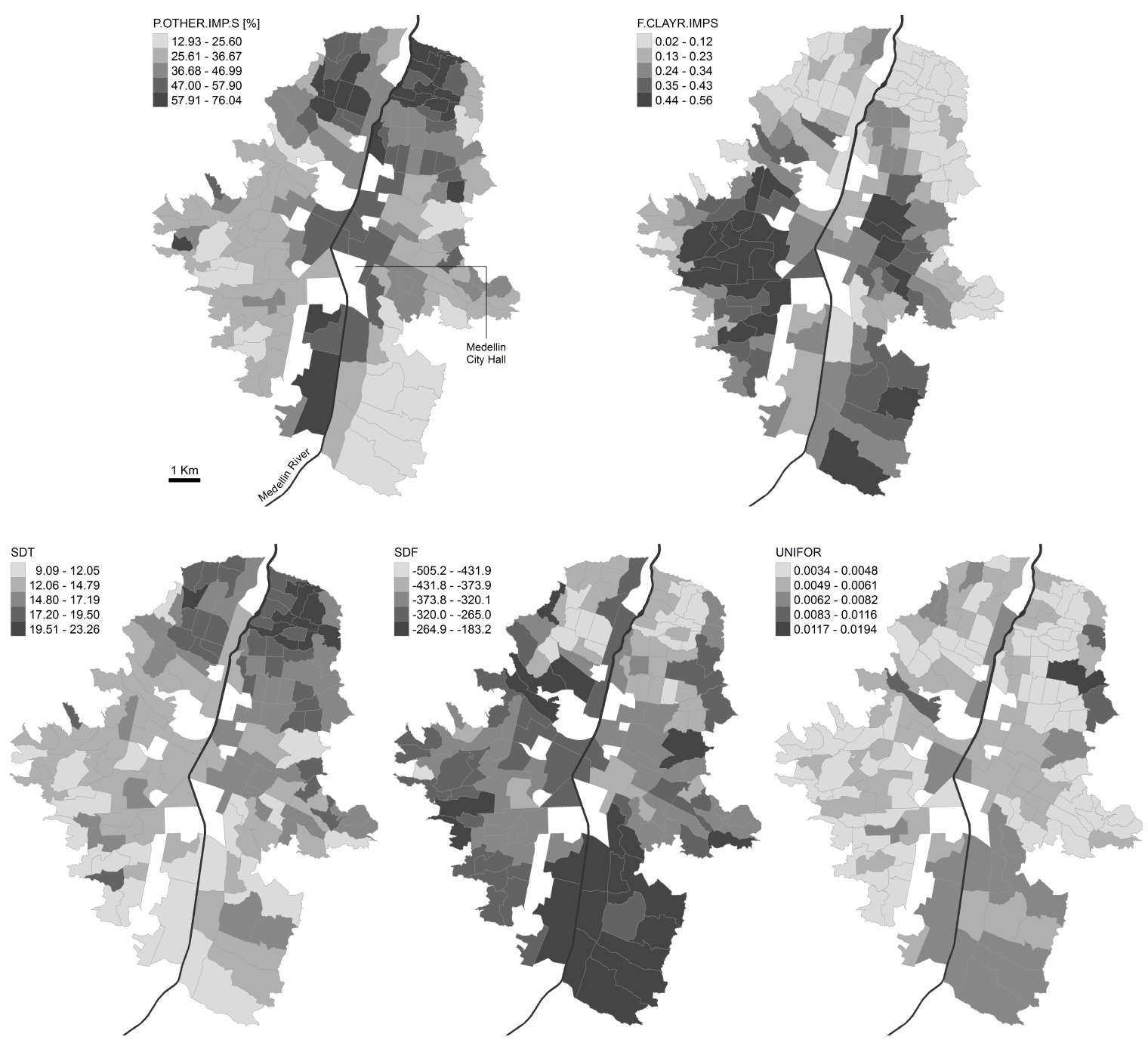


Figure 6. Choropleth maps of the best performing remote sensing variables added to the classic model specification of the average homicide rate per 100,000 people $(2010-2011)$ in Medellin at the analytical region level. All variables classified into intervals using the Natural Breaks method.

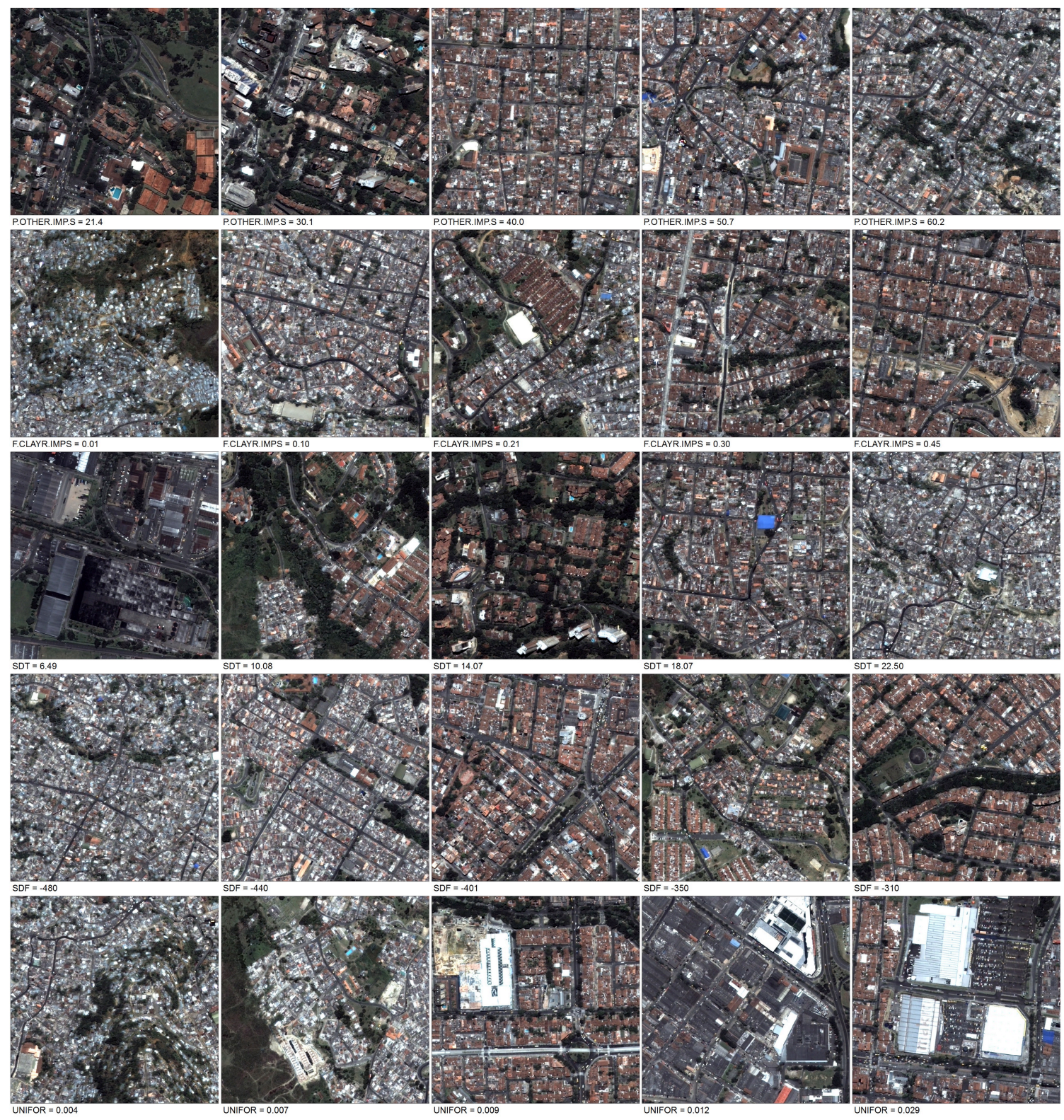

Figure 7. Square image tiles showing urban areas (500 x 500 meters) that have different values of the best performing remote sensing variables in model specification. From top to bottom: P.OTHER.IMP.S, F.CLAYR.IMPS, SDT, SDF, and UNIFOR. The tiles are organized from left to right according to increasing values of each variable.

\section{Conclusions}

The negative association between the Gini index of income and the average homicide rate at the analytical region level could indicate that the presence of different income groups in the same neighborhood could deter this type of criminal behavior. This association must be tested in other cities because it could support public housing policies that promote socially mixed neighborhoods to counter social exclusion and reduce crime. 
The areas with high homicide rates tended to be more heterogeneous in general and at short distances: they had higher local variation and less general homogeneity. The urban fabric was more crowded and cluttered, with small buildings or housing units located in close proximity to one another and with different roofing materials, and these regions lacked other homogeneous surfaces such as open green spaces, wide roads, water surfaces or large industrial or commercial buildings. These results are in agreement with the ideas of urban planning approaches such as CPTED and New Urbanism, but at the neighborhood scale when seen from the space: more heterogeneous and disordered urban layouts were associated with higher homicide rates.

The statistically significant correlations between the remote sensing variables and the homicide rates in Medellin do not necessarily imply causational effects. But these associations do inform about the physical aspects that are common in crime prone areas around this city and the results of this empirical analysis are in agreement with the theoretical expected effects. A heterogeneous, organic, cluttered urban layout can provide easy concealment and escape routes for committing homicide. Wide avenues, open spaces and regular street networks will increase the urban layout homogeneity at short distances. This phenomenon is in agreement with the ideas that were implemented in the "Second Empire" reforms by Baron Georges-Eugène Haussmann in Paris in the 19th century that shaped the modern city with its wide boulevards, open spaces and a network of large avenues, which facilitated the control of the city because the troops and the army could maneuver more quickly in these wider spaces than they could in the previous medieval urban layout (Clout, 1977).

The emergence of automated methods and tools for image feature extraction at object level such as FETEX opens up new possibilities of regional science analysis. This paper provides empirical evidence about the usefulness of remote sensing as a complementary information source for socioeconomic studies in urban settings. The remote sensing variables proved to be useful to quantify different aspects of the physical environment that relate to homicide rates in a city. These variables can add to classic crime explanatory models by quantifying complementary information on the urban composition and the spatial pattern of the urban layout. Spatial analysis of urban crime could benefit from this approach by including information on the physical environment using VHR imagery. Future work should focus in the development and assessment of new tools and techniques of image feature extraction for socioeconomic urban analysis. Regional scientists play an important role in directing that work to the most relevant topics.

\section{Acknowledgements}

This research was made possible by funding from EAFIT University and the Medellin City Hall Enlaza-Mundos program. The authors thank the anonymous reviewers and Hermilson Velázquez, Andrés Ramírez Hassan and Gustavo Canavire for their insightful observations and suggestions during the different stages of this project. The usual disclaimer applies.

\section{References}

Amrhein, C. G., \& Flowerdew, R. (1992). The effect of data aggregation on a Poisson regression model of Canadian migration. Environment and Planning A, 24(10), 1381-1391. doi:10.1068/a241381 
Anderson, C. A., \& Anderson, D. C. (1984). Ambient temperature and violent crime: Tests of the linear and curvilinear hypotheses. Journal of Personality and Social Psychology, 46(1), 91-97.

Anselin, L. (1988). Spatial econometrics: Methods and models (p. 284). Dordrecht: Kluwer Academic Publishers.

Anselin, L. (2005). Exploring spatial data with GeoDa: A Workbook (Revised., p. 226). Urbana, IL: Center for Spatially Integrated Social Science.

Anselin, L., Cohen, J., Cook, D., Gorr, W., \& Tita, G. (2000). Spatial analyses of crime. Criminal Justice, 4, $213-262$.

Anselin, L., Syabri, I., \& Kho, Y. (2006). GeoDa: An introduction to spatial data analysis. Geographical Analysis, 38(1), 5-22.

Arribas-Bel, D., \& Schmidt, C. R. (2013). Self-organizing maps and the US urban spatial structure. Environment and Planning B: Planning and Design, 40(2), 362-371. doi:10.1068/b37014

Atkinson, R. (2005). Occasional paper 1: Neighbourhoods and the impacts of social mix: crime, tenure diversification and assisted mobility. (pp. 1-36).

Balaguer, A., Ruiz, L. A., Hermosilla, T., \& Recio, J. A. (2010). Definition of a comprehensive set of texture semivariogram features and their evaluation for object-oriented image classification. Computers \& Geosciences, 36(2), 231-240. doi:10.1016/j.cageo.2009.05.003

Balaguer-Beser, A., Ruiz, L. A., Hermosilla, T., \& Recio, J. A. (2013). Using semivariogram indices to analyse heterogeneity in spatial patterns in remotely sensed images. Computers \& Geosciences, 50, 115-127. doi:10.1016/j.cageo.2012.08.001

Baraldi, A., \& Parmiggiani, F. (1995). An investigation of the textural characteristics associated with gray level cooccurrence matrix statistical parameters. IEEE Transactions on Geoscience and Remote Sensing, 33(2), 293-304. doi:10.1109/36.377929

Breetzke, G. D. (2012). The effect of altitude and slope on the spatial patterning of burglary. Applied Geography, 34, 66-75. doi:10.1016/j.apgeog.2011.10.017

Browning, C. R., Byron, R. A., Calder, C. A., Krivo, L. J., Kwan, M.-P., Lee, J.-Y., \& Peterson, R. D. (2010). Commercial density, residential concentration, and crime: Land use patterns and violence in neighborhood context. Journal of Research in Crime and Delinquency, 47(3), 329-357. doi:10.1177/0022427810365906

Butke, P., \& Sheridan, S. C. (2010). An analysis of the relationship between weather and aggressive crime in Cleveland, Ohio. Weather, Climate, and Society, 2(2), 127-139. doi:10.1175/2010WCAS1043.1

Carlsmith, J. M., \& Anderson, C. A. (1979). Ambient temperature and the occurrence of collective violence: A new analysis. Journal of Personality and Social Psychology, 37(3), 337-344.

Cerdá, M., Morenoff, J. D., Hansen, B. B., Tessari Hicks, K. J., Duque, L. F., Restrepo, A., \& Diez-Roux, A. V. (2012). Reducing violence by transforming neighborhoods: a natural experiment in Medellín, Colombia. American Journal of Epidemiology, 175(10), 1045-53. doi:10.1093/aje/kwr428

Clout, H. D. (1977). Urban Growth, 1500 - 1900. In H. D. Clout (Ed.), Themes in the Historical Geography of France (pp. 483-540). London: Academic Press Inc. Ltd. doi:10.1016/B978-0-12-175850-9.50020-X

Cohen, L. E., \& Felson, M. (1979). Social change and crime rate trends: A routine acivity approach. American Sociological Review, 44(4), 588-608. 
Cohn, E. G., \& Rotton, J. (2000). Weather, seasonal trends and property crimes in Minneapolis, 1987-1988. A moderator-variable time-series analysis of routine activities. Journal of Environmental Psychology, 20(3), 257-272. doi:10.1006/jevp.1999.0157

Cole, J. H., \& Marroquín Gramajo, A. (2009). Homicide rates in a cross-section of countries: evidence and interpretations. Population and Development Review, 35(October), 749-776.

Cozens, P. M. (2008). New Urbanism, crime and the suburbs: A review of the evidence. Urban Policy and Research, 26(4), 429-444. doi:10.1080/08111140802084759

Cullen, F. T., \& Agnew, R. (2011). The Chicago School: The city, social disorganization, and crime. In F. T. Cullen \& R. Agnew (Eds.), Criminological theory: past to present. Essential readings (4th ed., pp. 89-117). New York, Oxford: Oxford University Press. Retrieved from http://www.d.umn.edu/ jmaahs/Crime and Media/pdf files/cullen_agnew_socialD.pdf

DANE. (2010). Boletín Censo general 2005. Perfil Medellin, Antioquia. Bogota, Colombia. Retrieved from http://www.dane.gov.co/files/censo2005/PERFIL_PDF_CG2005/05001T7T000.PDF

DANE. (2012). Estimaciones de población 1985 - 2005 y proyecciones de población 2005 - 2020, total municipal por área. Bogota, Colombia. Retrieved from www.dane.gov.co

DeFrances, C. J., \& Titus, R. M. (1993). Urban planning and residential burglary outcomes. Landscape and Urban Planning, 26, 179-191.

DeFronzo, J. (1984). Climate and crime: Tests of an FBI assumption. Environment and Behavior, 16(2), 185-210.

Donovan, G. H., \& Prestemon, J. P. (2012). The effect of trees on crime in Portland, Oregon. Environment and Behavior, 44(1), 3-30. doi:10.1177/0013916510383238

Duque, J. C., Anselin, L., \& Rey, S. J. (2012). The max-p-regions problem. Journal of Regional Science, 52(3), 397419. doi:10.1111/j.1467-9787.2011.00743.x

Duque, J. C., Artís, M., \& Ramos, R. (2006). The ecological fallacy in a time series context: evidence from Spanish regional unemployment rates. Journal of Geographical Systems, 8(4), 391-410. doi:10.1007/s10109-0060033-x

Duque, J. C., Dev, B., Betancourt, A., \& Franco, J. L. (2011). ClusterPy: Library of spatially constrained clustering algorithms, Version 0.9.9. RiSE-group (Research in Spatial Economics). EAFIT University. (Available at: http://code.google.com/p/clusterpy/). Medellín: RiSE-group (Research in Spatial Economics). EAFIT University. Retrieved from http://code.google.com/p/clusterpy/

Duque, J. C., Royuela, V., \& Noreña, M. (2013). A stepwise procedure to determine a suitable scale for the spatial delineation of urban slums. In E. Fernandez \& F. Rubiera Morollón (Eds.), Defining the spatial scale in modern regional analysis. Advances in Spatial Science (pp. 237-254). Berlin Heidelberg: Springer-Verlag. doi:10.1007/978-3-642-31994-5_12

Field, S. (1992). The effect of temperature on crime. British Journal of Criminology, 32(3), 340-351.

Fiumi, L. (2012). Surveying the roofs of Rome. Journal of Cultural Heritage, 13, 304-313. doi:10.1016/j.culher.2011.12.003

Florax, R. J. G. M., Folmer, H., \& Rey, S. J. (2003). Specification searches in spatial econometrics: the relevance of Hendry's methodology. Regional Science and Urban Economics, 33, 557-579. doi:doi:10.1016/S01660462(03)00002-4 
Foster, S., Giles-Corti, B., \& Knuiman, M. (2010). Neighbourhood design and fear of crime: a social-ecological examination of the correlates of residents' fear in new suburban housing developments. Health \& Place, 16(6), 1156-1165. doi:10.1016/j.healthplace.2010.07.007

Fotheringham, A. S., \& Wong, D. W. S. (1991). The modifiable areal unit problem in multivariate statistical analysis. Environment and Planning A, 23(7), 1025-1044. doi:10.1068/a231025

Gaviria, A. (2000). Increasing returns and the evolution of violent crime: the case of Colombia. Journal of Development Economics, 61(1), 1-25. doi:10.1016/S0304-3878(99)00059-0

Giraldo Ramírez, J. (2010). Cambios en la interpretación, el comportamiento y las políticas públicas respecto a la violencia homicida en Medellín. In M. Hermelin, J. Giraldo Ramírez, \& A. Echeverry (Eds.), Medellín, Medio Ambiente, Urbanismo y Sociedad (pp. 294-318). Medellin: EAFIT University.

Haralick, R. M., Shanmugam, K., \& Dinstein, I. (1973). Textural features for image classification. IEEE Transactions on Systems, Man, and Cybernetics, SMC-3(6), 610-621.

Holin, M. J., Buron, L., Locke, G., \& Cortes, A. (2003). Interim assessment of the HOPE VI Program cross-site report (p. 175). Bethesda, MD. Retrieved from http://www.huduser.org/Publications/pdf/HOPE_VI_Cross_Site.pdf

Jain, S. (2008). Remote sensing application for property tax evaluation. International Journal of Applied Earth Observation and Geoinformation, 10(1), 109-121. doi:10.1016/j.jag.2007.10.008

Kawachi, I., Kennedy, B. P., \& Wilkinson, R. G. (1999). Crime: social disorganization and relative deprivation. Social Science \& Medicine (1982), 48(6), 719-31. Retrieved from http://www.ncbi.nlm.nih.gov/pubmed/10190635

Keizer, K., Lindenberg, S., \& Steg, L. (2008). The spreading of disorder. Science, 322(5908), 1681-1685. doi:10.1126/science.1161405

Kennedy, B. P., Kawachi, I., Prothrow-Stith, D., Lochner, K., \& Gupta, V. (1998). Social capital, income inequality, and firearm violent crime. Social Science \& Medicine (1982), 47(1), 7-17. Retrieved from http://www.ncbi.nlm.nih.gov/pubmed/9683374

Kuo, F. E., \& Sullivan, W. C. (2001). Environment and crime in the inner city. Does vegetation reduce crime? Environment and Behavior, 33(3), 343-367.

Kurtz, E. M., Koons, B. A., \& Taylor, R. B. (1998). Land use, physical deterioration, resident-based control, and calls for service on urban streetblocks. Justice Quarterly, 15(1), 121-150.

Levitt, S., \& Rubio, M. (2000). Understanding crime in Colombia and what can be done about it. FEDESARROLLO working paper No. 20 (No. 20) (pp. 1-42). Bogota, Colombia. Retrieved from http://econpapers.repec.org/RePEc:col:000123:003735

Leyk, S., Norlund, P. U., \& Nuckols, J. R. (2012). Robust assessment of spatial non-stationarity in model associations related to pediatric mortality due to diarrheal disease in Brazil. Spatial and Spatio-Temporal Epidemiology, 3(2), 95-105. doi:10.1016/j.sste.2012.04.003

Medellín Cómo Vamos. (2012). Análisis de la evolución de la calidad de vida en Medellín, 2008-2011. Seguridad ciudadana. (pp. 34-44). Medellín.

Medina, C., \& Martínez, H. (2003). Violence and drug prohibition in Colombia. CEDE working paper, Crisis States Programme. Los Andes University, No. 32 (No. 32) (pp. 1-24). Bogota, Colombia. Retrieved from http://eprints.lse.ac.uk/28238/ 
Medina, C., Posso, C., \& Tamayo, J. A. (2011). Costos de la violencia urbana y políticas públicas: algunas lecciones de Medellín. Borradores de Economía, (674), 1-42.

Menezes, T., Silveira-Neto, R., Monteiro, C., \& Ratton, J. L. (2013). Spatial correlation between homicide rates and inequality: Evidence from urban neighborhoods. Economics Letters, 120(1), 97-99.

doi:10.1016/j.econlet.2013.03.040

Morenoff, J. D., Sampson, R. J., \& Raudenbush, S. W. (2001). Neighborhood inequality, collective efficacy, and the spatial dynamics of urban violence. Criminology, 39(3), 517-560.

Openshaw, S. (1984). The modifiable areal unit problem, CATMOG 38 (Vol. 38., p. 40). Norwich: Geo Books. Retrieved from http://qmrg.org.uk/files/2008/11/38-maup-openshaw.pdf

Paelinck, J. H. P. (2000). On aggregation in spatial econometric modelling. Journal of Geographical Systems, 2(2), 157-165. doi:10.1007/PL00011452

Paelinck, J. H. P., \& Klaassen, H. (1979). Spatial econometrics. Farnborough, UK: Saxon House.

Popkin, S. J., Katz, B., Cunningham, M. K., Brown, K. D., Gustafson, J., \& Turner, M. A. (2004). A decade of HOPE VI: Research findings and policy challenges (p. 72). Washington, D.C. Retrieved from http://www.urban.org/UploadedPDF/411002_HOPEVI.pdf

Rey, S. J., Anselin, L., Folch, D. C., Arribas-Bel, D., Sastre Gutierrez, M. L., \& Interlante, L. (2011). Measuring spatial dynamics in metropolitan areas. Economic Development Quarterly, 25(1), 54-64. doi:10.1177/0891242410383414

Rey, S. J., \& Sastré-Gutiérrez, M. L. (2010). Interregional inequality dynamics in Mexico. Spatial Economic Analysis, 5(3), 277-298. doi:10.1080/17421772.2010.493955

Robinson, W. S. (1950). Ecological correlations and the behavior of individuals. American Sociological Review, 15(3), 351-357.

Roncek, D. W. (1981). Dangerous places: Crime and residential environment. Social Forces, 60(1), 74-96. doi: $10.2307 / 2577933$

Ruiz, L. A., Recio, J. A., Fernández-Sarría, A., \& Hermosilla, T. (2011). A feature extraction software tool for agricultural object-based image analysis. Computers and Electronics in Agriculture, 76(2), 284-296. doi:10.1016/j.compag.2011.02.007

Salleh, S. A., Mansor, N. S., Yusoff, Z., \& Nasir, R. A. (2012). The crime ecology: Ambient temperature vs. spatial setting of crime burglary. Procedia - Social and Behavioral Sciences, 42, 212-222.

doi:10.1016/j.sbspro.2012.04.184

Sánchez Torres, F., \& Núñez Méndez, J. (2001). Determinantes del crimen violento en un país altamente violento: el caso de Colombia. CEDE working paper, Los Andes University, No. 2001-02 (No. 2001-02). Documento CEDE (p. 45). Bogota, Colombia.

Shaw, C. R., \& McKay, H. D. (1942). Juvenile Delinquency and Urban Areas. Chicago: University of Chicago Press.

Shu, S. C. F., \& Huang, J. N. H. (2003). Spatial configuration and vulnerability of residential burglary: A case study of a city in Taiwan. In 4th International Space Syntax Symposium (pp. 46.1-46.14). London.

SISC. (2010). Dinámica del homicidio en 2009 (p. 102). Medellin. 
Sorg, E. T., \& Taylor, R. B. (2011). Community-level impacts of temperature on urban street robbery. Journal of Criminal Justice, 39(6), 463-470. doi:10.1016/j.jcrimjus.2011.08.004

Sparks, C. S. (2011). Violent crime in San Antonio, Texas: An application of spatial epidemiological methods. Spatial and Spatio-Temporal Epidemiology, 2(4), 301-309. doi:10.1016/j.sste.2011.10.001

Stark, R. (1987). Deviant places: A theory of the ecology of crime. Criminology, (25), 893-909.

Stow, D. A., Lippitt, C. D., \& Weeks, J. R. (2010). Geographic object-based delineation of neighborhoods of Accra, Ghana using Quickbird satellite imagery. Photogrammetric Engineering and Remote Sensing, 76(8), 907914.

Sutton, R. N., \& Hall, E. L. (1972). Texture Measures for Automatic Classification of Pulmonary Disease. IEEE Transactions on Computers, C-21(7), 667-676. doi:10.1109/T-C.1972.223572

Taubenböck, H., Wurm, M., Setiadi, N., Gebert, N., Roth, A., Strunz, G., ... Dech, S. (2009). Integrating remote sensing and social science - The correlation of urban morphology with socioeconomic parameters. In IEEE (Ed.), 2009 Urban Remote Sensing Joint Event. London.

Taylor, R. B., \& Harrell, A. V. (1996). Physical Environment and Crime (p. 32). Rockville.

Troy, A., Grove, J. M., \& O'Neil-Dunne, J. (2012). The relationship between tree canopy and crime rates across an urban rural gradient in the greater Baltimore region. Landscape and Urban Planning, 106, 262-270.

Wang, F., \& Arnold, M. T. (2008). Localized income inequality, concentrated disadvantage and homicide. Applied Geography, 28(4), 259-270. doi:10.1016/j.apgeog.2008.07.004

Weeks, J. R. (2003). Does nighttime lighting deter crime? An analysis of remotely-sensed imagery and crime data. In V. Mesev (Ed.), Remotely-sensed cities (pp. 355-372). London: Taylor \& Francis.

Weeks, J. R., Hill, A. G., Stow, D. A., Getis, A., \& Fugate, D. (2006). The Impact of Neighborhood Structure on Health Inequalities in Accra, Ghana. In Annual Meeting of the Population Association of America (pp. 1-34). Los Angeles: San Diego State University.

Weeks, J. R., Hill, A. G., Stow, D., Getis, A., \& Fugate, D. (2007). Can we spot a neighborhood from the air? Defining neighborhood structure in Accra, Ghana. GeoJournal, 69(1-2), 9-22. doi:10.1007/s10708-007-9098-4

Wilcox, P., Quisenberry, N., Cabrera, D. T., \& Jones, S. (2004). Busy places and broken windows? Toward defining the role of physical structure and process in community crime models. The Sociological Quarterly, 45(2), 185-207.

Wilson, J. Q., \& Kelling, G. L. (1982). Broken windows: The police and neighborhood safety. Atlantic Monthly, 249(3), 29-38. Retrieved from http://www.theatlantic.com/magazine/archive/1982/03/brokenwindows/4465/

Wolfe, M. K., \& Mennis, J. (2012). Does vegetation encourage or suppress urban crime? Evidence from Philadelphia, PA. Landscape and Urban Planning, 108(2-4), 112-122. doi:10.1016/j.landurbplan.2012.08.006

Ye, X., \& Wu, L. (2011). Analyzing the dynamics of homicide patterns in Chicago: ESDA and spatial panel approaches. Applied Geography, 31(2), 800-807. doi:10.1016/j.apgeog.2010.08.006

Ye, Y., Zhang, H., Liu, K., \& Wu, Q. (2011). Research on the influence of site factors on the expansion of construction land in the Pearl River Delta, China: By using GIS and remote sensing. International Journal of Applied Earth Observation and Geoinformation. doi:10.1016/j.jag.2011.10.012 
